\title{
Conformational study of 1,2-diaminoethane by combined ab initio MO calculations and Raman spectroscopy
}

\author{
L.A.E. Batista de Carvalho* ${ }^{*}$ L.E. Lourenço, M.P.M Marques \\ Unidade I\&D Química-Física Molecular, Fac. Ciências e Tecnologia, Universidade de Coimbra, P-3049 Coimbra, Portugal
}

Received 24 August 1998

\begin{abstract}
A conformational analysis of the linear polyamine 1,2-diaminoethane was performed by both Raman spectroscopy and ab initio SCF-MO methods (with and without inclusion of water solvent effects). Ten different conformers were detected by ab initio calculations, the most stable ones being $\mathrm{TGG}^{\prime}$ and $\mathrm{GGG}^{\prime}$. When considering the solvent, the conformations having a higher dipole moment were found to be favoured over the less polar ones. The Raman spectra of this amine obtained for the pure liquid, the aqueous solution and the solid sample, allowed to conclude that its conformational preferences are determined by the relative importance of intra- versus intermolecular hydrogen bonds. (C) 1999 Elsevier Science B.V. All rights reserved.
\end{abstract}

Keywords: 1,2-Diaminoethane; Conformational analysis; Raman spectroscopy; Ab initio MO

\section{Introduction}

1,2-diaminoethane $\left(\mathrm{H}_{2} \mathrm{~N}\left(\mathrm{CH}_{2}\right)_{2} \mathrm{NH}_{2}\right)$ and the larger similar molecules 1,3-diaminopropane and 1,4-diaminobutane (putrescine) are widely used as chelating agents for some metal ions, and are precursors of biologically relevant polyamines (e.g. spermidine and spermine) that play an essential role in cell growth and differentiation in eukaryotic organisms. Moreover, some metal complexes (e.g. $\mathrm{Pt}^{2+}$ ) formed with these amines are known to display anticancer properties through DNA-binding. However, the exact nature of the biochemical mechanisms through which they act is still unknown, and has been the topic of intense research in recent years.

Rotational isomerism in alkylamines is influenced

\footnotetext{
* Corresponding author. Tel.: + 35139 826541; fax: + 35139 826541.

E-mail address: labc@gemini.ci.uc.pt (L.A.E. Batista de Carvalho)
}

by different factors, from steric, dipolar and hyperconjugative effects to hydrogen bonding. Moreover, the relative importance of intra versus intermolecular interactions has proved to be determinant of the conformational preferences of this kind of systems, either as pure compounds or in solution [1-7].

Several conformational studies have been reported in the literature for 1,2-diaminoethane, the simplest linear polyamine. While it adopts an all-trans geometry in the solid state $[8,9]$, it was shown - by electron diffraction and microwave methods $[10,11]-$ to display rotational isomerism in the gaseous state, the predominant species being the gauche conformers relative to the central $\mathrm{C}-\mathrm{C}$ bond. In the liquid phase, in turn, no conclusive answers have yet been obtained to explain the conformational behaviour of this diamine.

The analysis of the FTIR and Raman spectra of this molecule and its deuterated derivatives led to the detection of distinct conformations in the pure liquid [12-15]. These results have been interpreted in terms 
Table 1

$\mathrm{Ab}$ initio relative energies, populations and dipole moments $(\mu)$ calculated for the distinct conformers of 1,2-diaminoethane

\begin{tabular}{|c|c|c|c|c|c|}
\hline \multirow[t]{2}{*}{ Conformer (symmetry) } & \multirow[t]{2}{*}{$\mu^{\mathrm{a}}(\mathrm{D})$} & \multicolumn{4}{|c|}{$\Delta E / \mathrm{kJ} \mathrm{mol}^{-1}$ (population, $\left.\%\right)^{\mathrm{b}}$} \\
\hline & & $3-21 G\left(N^{*}\right)$ & $\mathrm{MP} 2 / 6-31 \mathrm{G}^{* *}$ & $\begin{array}{l}\mathrm{SCRF}^{\mathrm{c}} \\
3-21 \mathrm{G}\left(\mathrm{N}^{*}\right)\end{array}$ & $\begin{array}{l}\text { SCRF } \\
\text { MP2/6-31G** }\end{array}$ \\
\hline TGG $^{\prime}\left(C_{1}\right)$ & 2.98 & $0(52.5)$ & $0(41.0)$ & $0(63.4)$ & $0(69.4)$ \\
\hline $\mathrm{GGG}^{\prime}\left(\mathrm{C}_{1}\right)$ & 2.40 & $1.62(27.3)$ & $0.73(30.5)$ & $2.19(26.2)$ & $3.13(19.6)$ \\
\hline TGG $\left(\mathrm{C}_{1}\right)$ & 2.77 & $8.27(1.9)$ & $5.93(3.8)$ & $7.33(3.3)$ & $7.35(3.6)$ \\
\hline GGG $\left(\mathrm{C}_{2}\right)$ & 0.31 & $5.99(4.7)$ & $2.71(13.8)$ & $10.72(0.8)$ & $7.83(3.0)$ \\
\hline TTG $\left(\mathrm{C}_{1}\right)$ & 2.77 & $6.94(3.2)$ & $7.77(1.8)$ & $7.24(3.4)$ & $8.80(2.0)$ \\
\hline $\mathrm{GG}^{\prime} \mathrm{G}\left(\mathrm{C}_{2}\right)$ & 1.95 & $20.07(0)$ & $17.38(0)$ & $21.64(0)$ & $20.48(0)$ \\
\hline TTT $\left(\mathrm{C}_{2 \mathrm{~h}}\right)$ & 0 & $5.32(3.1)$ & $5.35(2.4)$ & $10.17(0.5)$ & $10.52(0.5)$ \\
\hline TGT $\left(\mathrm{C}_{2}\right)$ & 0.45 & $8.11(2.0)$ & $5.48(4.5)$ & $12.92(0.4)$ & $10.56(1.0)$ \\
\hline GTG $\left(\mathrm{C}_{2}\right)$ & 2.32 & $7.82(2.2)$ & $9.30(1.0)$ & $9.32(1.5)$ & $11.33(0.7)$ \\
\hline $\mathrm{GTG}^{\prime}\left(\mathrm{C}_{\mathrm{i}}\right)$ & 0 & $6.99(3.1)$ & $8.66(1.2)$ & $11.83(0.5)$ & $13.84(0.2)$ \\
\hline
\end{tabular}

${ }^{\mathrm{a}}$ Calculated at the SCRF (water) //MP2/6-31G** level $\left(1 \mathrm{D}=1 / 3 \times 10^{-2} \mathrm{C} \mathrm{m}\right)$.

${ }^{\mathrm{b}}$ Calculated at $25^{\circ} \mathrm{C}$.

${ }^{\mathrm{c}}$ In Water, $\epsilon^{25^{\circ} \mathrm{C}}=78.54$.

of the rotation around the central $\mathrm{C}-\mathrm{C}$ bond, but no reference has been made as to the orientation of the nitrogen electron lone-pairs.

Previously performed ab initio MO calculations found ten different energy minima for this molecule [16-19]. Nevertheless, no attempts have been made either to mimetize aqueous solution conditions or to obtain the calculated vibrational spectra of the distinct conformers. Also, there are no reports on a normal coordinate analysis performed for this system.

In the present work, 1,2-diaminoethane was studied by both Raman spectroscopy and ab initio MO calculations. A conformational analysis was performed, based on the vibrational data and the theoretical calculations - geometries, wavenumbers and intensities for both the isolated molecule and considering a solvent (water) reaction field, in order to understand the conformational changes caused by the presence of the solvent and the factors that govern them. A complete assignment of the vibrational spectra was made, for both the non-deuterated and $\mathrm{N}$-deuterated molecules. A normal coordinate analysis was carried out, using local symmetry coordinates and the calculated $a b$ initio force field.

\section{Experimental}

The ab initio SCF-MO calculations were carried out as previously reported [20], using the GAUSSIAN 94 program [21], with the split valence basis sets $3-21 \mathrm{G}\left(\mathrm{N}^{*}\right), 6-31 \mathrm{G}^{* *}$ and MP2/6-31G** [22-28]. Only the geometries with skeletal dihedral angles equal to $60^{\circ}, 180^{\circ}$ and $-60^{\circ}$ were considered for the conformational search. The presence of the solvent (water) was simulated by performing Self-Consistent Reaction Field (SCRF) ab initio MO calculations [29]. The normal coordinate analysis of the molecule was undertaken using the GF Wilson's method.

Raman spectra were recorded on a Spex 1403 Ramalog double spectrometer, as published earlier [7]. The light source was a Spectra Physics $\mathrm{Ar}^{+}$ laser whose output at $514.5 \mathrm{~nm}$ was adjusted to provide $100 \mathrm{~mW}$ at the sample position.

1,2-diaminoethane (redistilled, $99.5+\%$ ) was obtained from Aldrich and used without further purification. 1,2-diaminoethane- $\mathrm{N}-\mathrm{d}_{4}$ was prepared by repeatedly stirring a $1: 1$ mixture of the pure compound and $\mathrm{D}_{2} \mathrm{O}$ for ca. $1 \mathrm{~h}$, followed by distillation.

\section{Results and discussion}

\subsection{Ab initio $M O$ results}

Ten distinct minima were found for 1,2-diaminoethane (Table 1, Fig. 1). The most populated 


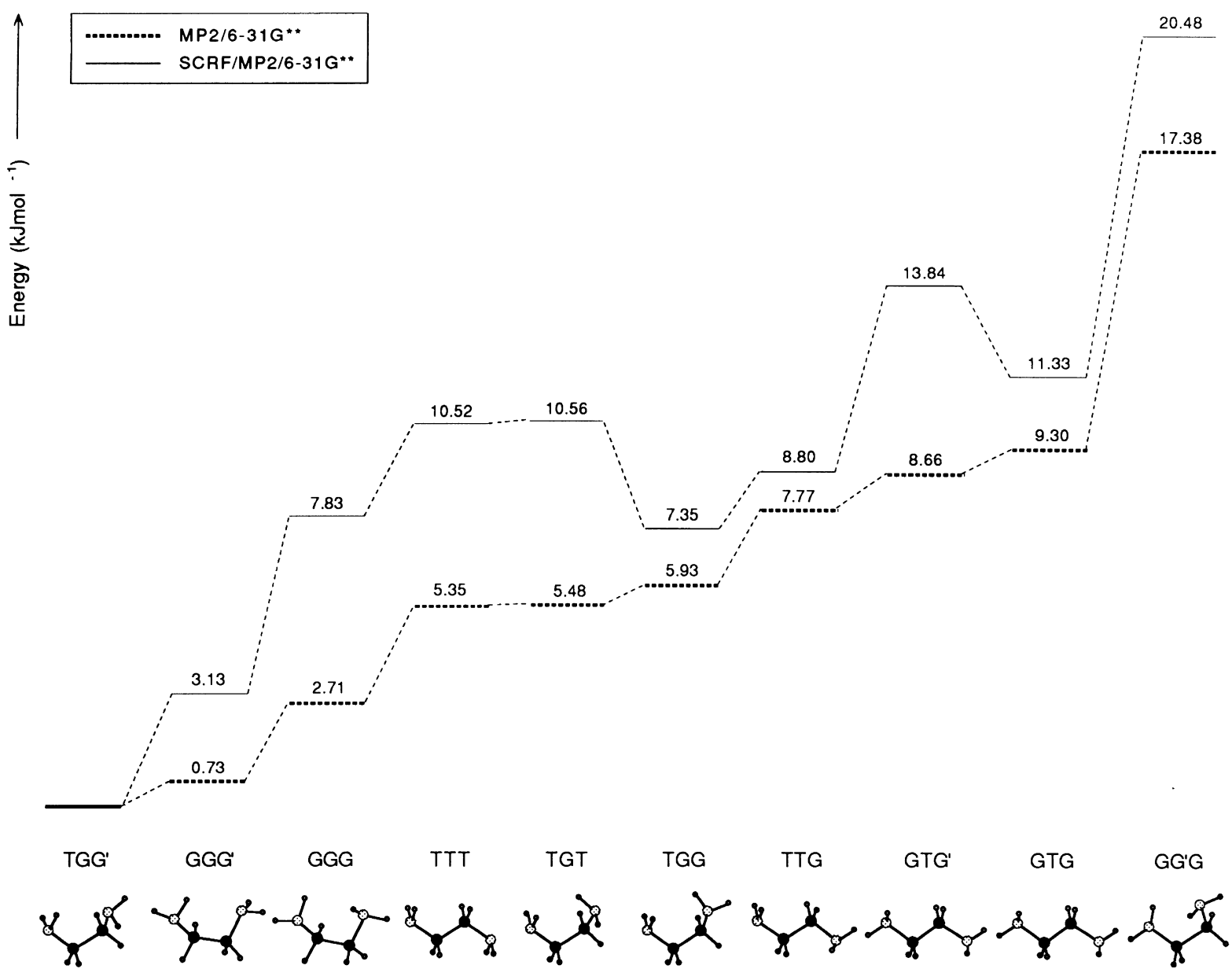

Fig. 1. Schematic representation of the conformational energies calculated for 1,2-diaminoethane.

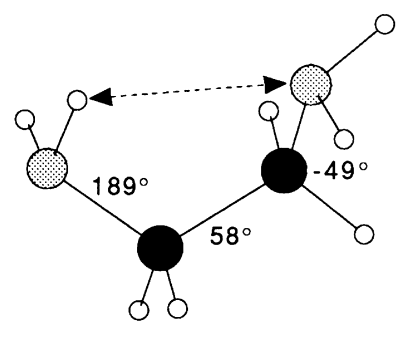

TGG'

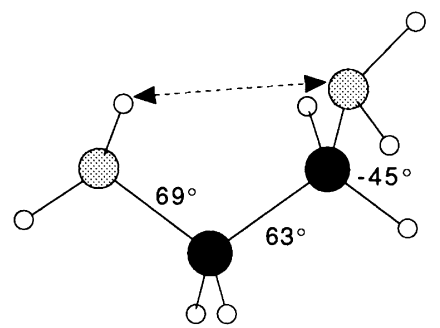

GGG'

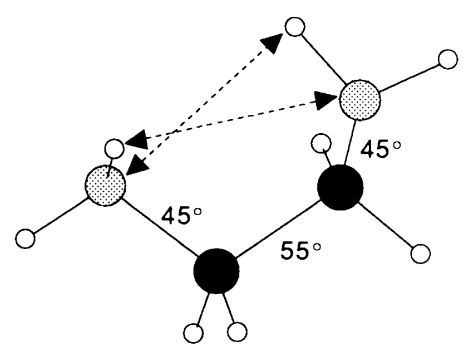

GGG

Fig. 2. Schematic representation of the most stable conformers of 1,2-diaminoethane, displaying intramolecular $(\mathrm{N}) \mathrm{H} \cdots: \mathrm{N}$ interactions. 


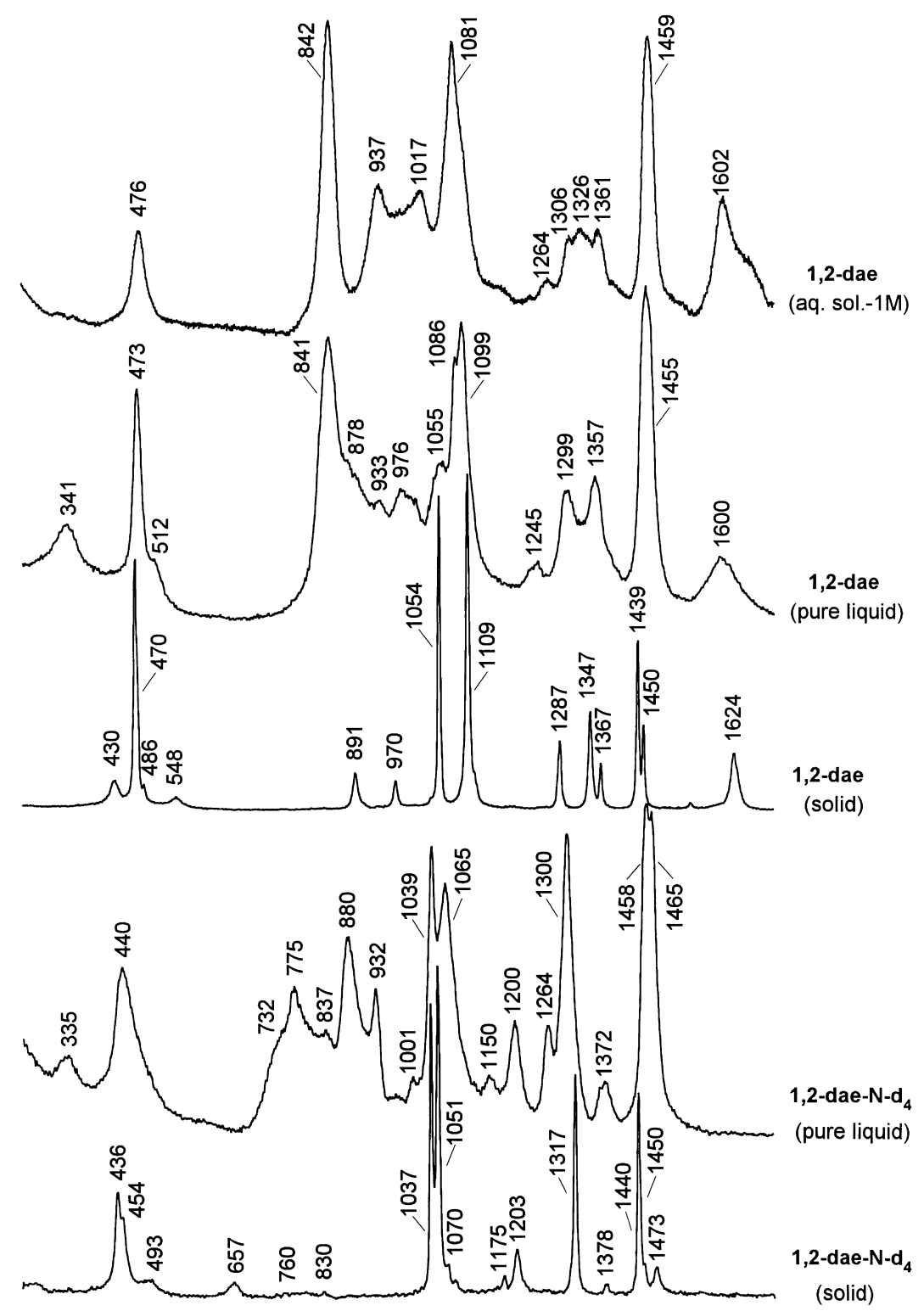

Fig. 3. Raman spectra $\left(250-1700 \mathrm{~cm}^{-1}\right)$ of 1,2-diaminoethane (1,2-dae) and 1,2-diaminoethane- $\mathrm{N}-\mathrm{d}_{4}\left(1,2-\right.$ dae- $\left.^{-} \mathrm{N}-\mathrm{d}_{4}\right)$ in aqueous solution $(1 \mathrm{M})$, pure liquid $(293 \mathrm{~K})$ and solid phase.

conformers - $\mathrm{TGG}^{\prime}$ and $\mathrm{GGG}^{\prime}$ - display gauche skeletal orientations, that allow the occurrence of stabilising intramolecular $(\mathrm{N}) \mathrm{H} \cdots: \mathrm{N}$ hydrogen bonds (Fig. 2). The presence of this kind of interaction is confirmed by both the calculated geometrical parameters (available from the authors upon request) - namely the NCCN and :NCC dihedral angles
(Fig. 2) and the CNH bond angles - and the changes detected in the Mulliken charges of the atoms involved.

It was verified that the smaller basis set $3-21 \mathrm{G}\left(\mathrm{N}^{*}\right)$ reproduces rather well the energies of the trans conformations relative to the central $\mathrm{C}-\mathrm{C}$ bond. However, inclusion of electron correlation effects 
Table 2

Raman experimental and calculated wavenumbers $\left(\mathrm{cm}^{-1}\right)$ for some conformers of 1,2-diaminoethane (1,2-dae) and 1,2-diaminoethane-N-d $\left(1,2-\right.$ dae- $\left.-\mathrm{N}-\mathrm{d}_{4}\right)$

\begin{tabular}{|c|c|c|c|c|c|c|c|c|}
\hline \multicolumn{5}{|c|}{ Experimental } & \multicolumn{3}{|c|}{ Calculated $^{\mathrm{a}}$} & \multirow{3}{*}{$\begin{array}{l}\text { Approximate descriptions and } \\
\text { PED }(\%) \text { values }{ }^{\text {b }}\end{array}$} \\
\hline \multicolumn{3}{|l|}{ 1,2-dae } & \multicolumn{2}{|c|}{ 1,2-dae-N-d ${ }_{4}$} & \multicolumn{3}{|l|}{ 1,2-dae } & \\
\hline Aq. Sol. & Liquid & Solid & Liquid & Solid & TGG $^{\prime}$ & $\mathrm{GGG}^{\prime}$ & TTT & \\
\hline \multirow[t]{3}{*}{3370} & 3360 & 3335 & & & 3444 & 3447 & $3436 \mathrm{Bg}$ & $\mathrm{NH}_{2}$ antisym. stretching (100) \\
\hline & & & & & 3425 & & & \\
\hline & & 3252 & & & & & & \\
\hline \multirow[t]{4}{*}{3310} & 3300 & 3169 & & & 3347 & 3349 & $3340 \mathrm{Ag}$ & $\mathrm{NH}_{2}$ sym. stretching (100) \\
\hline & & & & & 3333 & & & \\
\hline & 3190 & & & & & & & $\begin{array}{l}\mathrm{FR}^{\mathrm{c}}\left(2 \times \mathrm{NH}_{2} \text { sciss. }+\mathrm{NH}_{2}\right. \\
\text { sym. str. })\end{array}$ \\
\hline & & & & & 2981 & 2990 & & \\
\hline \multirow[t]{2}{*}{2942} & 2917 & 2909 & 2933 & 2930 & 2958 & 2959 & $2962 \mathrm{Bg}$ & $\mathrm{CH}_{2}$ antisym. stretching (100) \\
\hline & & 2897 & & 2893 & & & & $\begin{array}{l}\mathrm{FR}^{\mathrm{c}}\left(2 \times \mathrm{CH}_{2} \text { sciss. }+\mathrm{CH}_{2}\right. \\
\text { sym. str. })\end{array}$ \\
\hline \multirow[t]{5}{*}{2880} & 2858 & 2856 & 2872 & 2868 & 2919 & 2883 & $2915 \mathrm{Ag}$ & $\mathrm{CH}_{2}$ sym. stretching (100) \\
\hline & & & & & 2867 & 2841 & & \\
\hline & & & 2513 & 2504 & & & & $\mathrm{ND}_{2}$ antisym. stretching \\
\hline & & & 2434 & 2429 & & & & $\mathrm{ND}_{2}$ sym. stretching \\
\hline & & & 2371 & 2367 & & & & $\mathrm{ND}_{2}$ sym. stretching \\
\hline \multirow[t]{3}{*}{1602} & 1600 & 1624 & & & 1602 & 1588 & $1594 \mathrm{Ag}$ & $\mathrm{NH}_{2}$ scissoring (100) \\
\hline & & & & & 1589 & 1577 & & \\
\hline & & & 1465 & 1473 & 1463 & 1473 & & $\mathrm{CH}_{2}$ scissoring \\
\hline \multirow[t]{2}{*}{1459} & 1455 & 1450 & 1458 & 1450 & 1447 & 1457 & $1441 \mathrm{Ag}$ & $\mathrm{CH}_{2}$ scissoring (100) \\
\hline & & 1439 & & 1440 & & & & $\mathrm{CH}_{2}$ scissoring \\
\hline 1361 & 1357 & 1367 & 1372 & 1378 & 1343 & 1353 & $1352 \mathrm{Ag}$ & $\mathrm{CH}_{2}$ wagging (100) \\
\hline 1326 & & 1347 & & & 1336 & 1293 & $1319 \mathrm{Ag}$ & $\begin{array}{l}\mathrm{CH}_{2} \text { twisting (55) }+\mathrm{NH}_{2} \\
\text { twisting (25) }\end{array}$ \\
\hline \multirow[t]{2}{*}{1306} & 1299 & & & & 1272 & 1277 & & $\mathrm{CH}_{2}$ twisting $+\mathrm{NH}_{2}$ twisting \\
\hline & & & 1300 & 1317 & & & & $\mathrm{CH}_{2}$ wagging \\
\hline \multirow[t]{4}{*}{1264} & 1245 & 1287 & & & & & $1257 \mathrm{Bg}$ & $\begin{array}{l}\mathrm{NH}_{2} \text { twisting (31) }+\mathrm{CH}_{2} \\
\text { twisting (30) }\end{array}$ \\
\hline & & & 1264 & & & & & $\mathrm{CH}_{2}$ twisting \\
\hline & & & 1200 & 1203 & & & & $\mathrm{ND}_{2}$ deformation \\
\hline & & & 1150 & 1175 & & & & \\
\hline \multirow[t]{5}{*}{1081} & 1099 & 1109 & 1065 & 1051 & & & $1086 \mathrm{Ag}$ & $\mathrm{CN}$ stretching (58) \\
\hline & 1086 & & & & 1069 & 1086 & & CN stretching \\
\hline & 1055 & 1054 & 1039 & 1037 & & & $1039 \mathrm{Ag}$ & $\mathrm{CH}_{2}-\mathrm{CH}_{2}$ stretching (67) \\
\hline & & & 1001 & 1070 & & & & $\mathrm{ND}_{2}$ twisting \\
\hline & 976 & & 932 & & 970 & 1024 & & $\mathrm{CN}$ stretching \\
\hline \multirow[t]{3}{*}{937} & 933 & 970 & & & & & $906 \mathrm{Bg}$ & $\begin{array}{l}\mathrm{CH}_{2} \text { rocking }(55)+\mathrm{ND}_{2} \\
\text { twisting (45) }\end{array}$ \\
\hline & & & 880 & & & & & $\mathrm{CN}$ stretching \\
\hline & 878 & & & & 884 & 873 & & $\begin{array}{l}\mathrm{NH}_{2} \text { wagging }+\mathrm{CH}_{2}-\mathrm{CH}_{2} \\
\text { stretching }\end{array}$ \\
\hline \multirow[t]{5}{*}{842} & 841 & 891 & & & 792 & 804 & $829 \mathrm{Ag}$ & $\begin{array}{l}\mathrm{NH}_{2} \text { wagging }(80)+\mathrm{CN} \\
\text { stretching }(20)\end{array}$ \\
\hline & & & 775 & 830 & & & & $\mathrm{CH}_{2}$ rocking \\
\hline & & & 732 & 760 & & & & $\mathrm{ND}_{2}$ wagging \\
\hline & & & & 657 & & & & \\
\hline & & 548 & & & & & & $\begin{array}{l}\left(470+88 \mathrm{~cm}^{-1}\right) \text { combination } \\
\text { mode }\end{array}$ \\
\hline
\end{tabular}


Table 2 (continued)

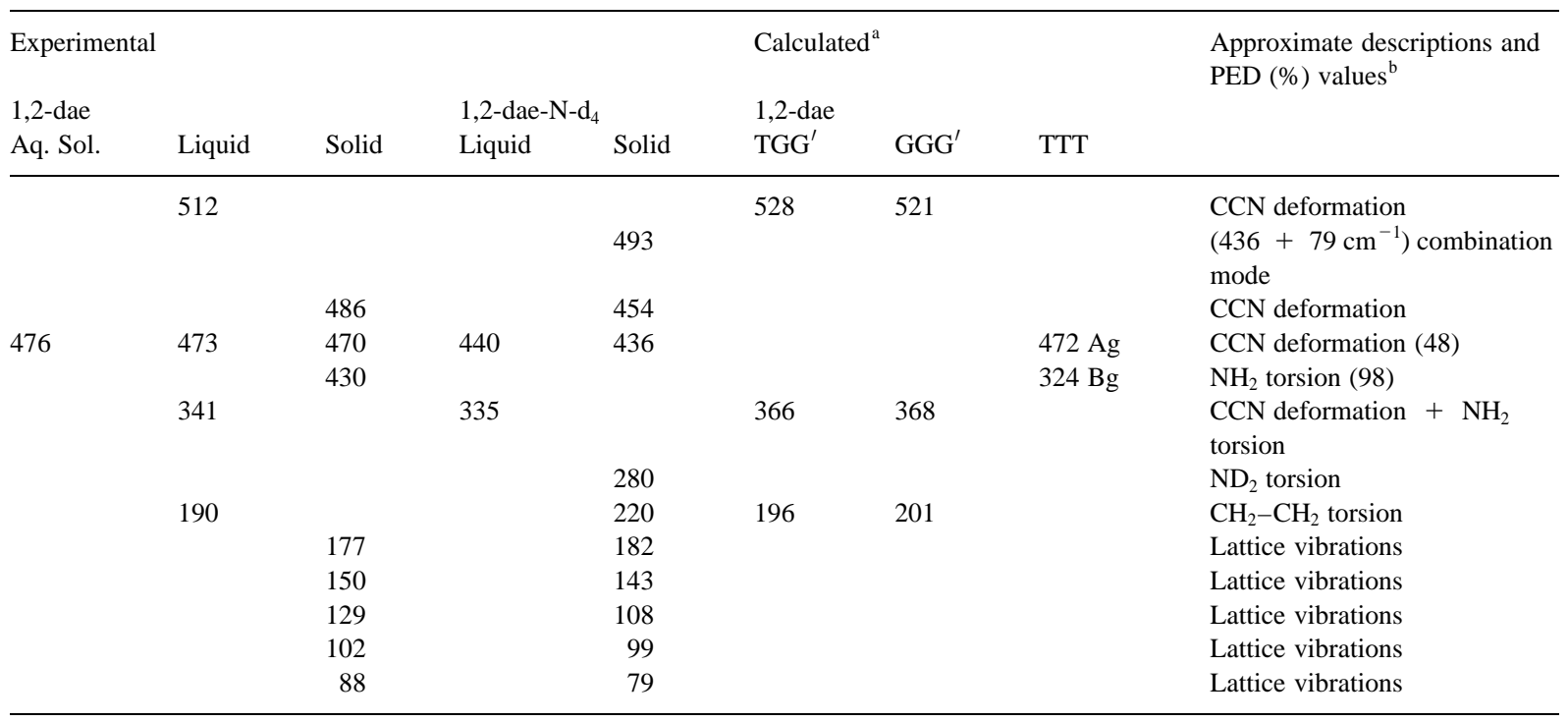

${ }^{\mathrm{a}} \mathrm{MP} 2 / 6-31 \mathrm{G}^{* *}$ level; scaled by a factor of 0.9370 [31] for all but the five low-frequency vibrations.

${ }^{\mathrm{b}}$ Potential Energy Distribution calculated for the TTT conformer.

${ }^{\mathrm{c}}$ FR: Fermi resonance.

was found to be relevant for a proper mimetization of the $(\mathrm{N}) \mathrm{H} \cdots: \mathrm{N}$ interactions. Indeed, the GGG conformer, where two interactions of this kind can occur simultaneously (Fig. 2), displays the largest energy lag between the $3-21 \mathrm{G}\left(\mathrm{N}^{*}\right)$ and the MP2/6$31 \mathrm{G}^{* *}$ values (Table 1). These hydrogen bonds were found to be of rather moderate strength, the $\mathrm{NH} \cdots \mathrm{N}$ distances calculated in the present work being 247 and $241 \mathrm{pm}$ for conformers $\mathrm{TGG}^{\prime}$ and $\mathrm{GGG}^{\prime}$, respectively, that compare well with the microwave values of 264 and $252 \mathrm{pm}$ [11].

In accordance with experimental results [10,11] and with previous theoretical studies on similar systems $[5,20,26]$, values close to $115^{\circ}$ and $109^{\circ}$ for the $\mathrm{CCN}$ bond angles were obtained for those geometries displaying either a $\mathrm{T}$ or a $\mathrm{G}$ orientation of the nitrogen electron lone-pair relative to the $\mathrm{C}-\mathrm{C}$ bond, respectively. In fact, the ab initio results now obtained are in good agreement with microwave [11] and electron diffraction studies [10], regarding both the geometrical parameters $\left(\mathrm{NCCN}_{\text {exp }}=63 \pm 2^{\circ}\right.$ versus $\mathrm{NCCN}_{\text {calc }}\left(\mathrm{MP} 2 / 6-31 \mathrm{G}^{* *}\right)=58.1^{\circ}$, for the most populated $\mathrm{TGG}^{\prime}$ conformer) and the rotational constants $\left((A, \mathrm{~B}, C)_{\exp }=14.355,5.125,4.356 \mathrm{GHz}\right.$ versus $(A$, $\mathrm{B}, C)_{\mathrm{calc}}\left(\mathrm{MP} 2 / 6-31 \mathrm{G}^{* *}\right)=14.281,5.246,4.427 \mathrm{GHz}$, for the same conformer). As to the dipole moments, there is a fair agreement between the calculated (Table 1$)$ and the experimental values [11] $\left(\mu_{\exp }=\right.$ $1.77 \mathrm{D}$ versus $\mu_{\text {calc }}\left(\mathrm{MP} 2 / 6-31 \mathrm{G}^{* *}\right)=2.21 \mathrm{D}$, and $\mu_{\text {exp }}=2.20 \mathrm{D}$ versus $\mu_{\text {calc }}\left(\mathrm{MP} 2 / 6-31 \mathrm{G}^{* *}\right)=2.75 \mathrm{D}$, for $\mathrm{GGG}^{\prime}$ and $\mathrm{TGG}^{\prime}$ conformers, respectively). These values are in accordance with the well known positive deviation of the calculated dipole moments from the experimental values [30]. Although the ab initio results point to an inversion of the populations of the two most stable conformers, $\mathrm{TGG}^{\prime}$ and $\mathrm{GGG}^{\prime}$ (Table 1), relative to a previous microwave study [11], the rather small energy lag between them can easily explain this difference.

Inclusion of water solvent effects - SCRF approach - was found not to affect significantly the geometry of the conformers, but predicts a significant stabilisation of the ones displaying a higher dipole moment, and the symmetric arrangements, with a zero or next-tozero dipole moment are clearly not favoured (Fig. 1) e.g. conformer GGG ( $\mu=0.31 \mathrm{D})$ is destabilised by $5.1 \mathrm{~kJ} \mathrm{~mol}^{-1}$ relative to TGG $(\mu=2.77 \mathrm{D})$. The asymmetric $\mathrm{TGG}^{\prime}$ conformer was still found to be the most stable one at this level of calculation, displaying, however, a higher energy difference to 
the next most populated conformation, $\mathrm{GGG}^{\prime}$ (3.13 versus $0.73 \mathrm{~kJ} \mathrm{~mol}^{-1}$, Fig. 1).

\subsection{Vibrational analysis}

Fig. 3 shows the Raman spectra of 1,2-diaminoethane and 1,2-diaminoethane- $\mathrm{N}-\mathrm{d}_{4}$ for the solid, the pure liquid and the aqueous solution, in the $250-1700 \mathrm{~cm}^{-1}$ region. Experimental Raman wavenumbers of these systems are presented in Table 2, along with the calculated values (MP2/6-31G**level) for some conformers of the non-deuterated molecule. It was verified that the wavenumbers obtained at any level of calculation do not change by inclusion of the SCRF approach. The agreement between the experimental and calculated wavenumbers, using the recently proposed scaling factors of Scott and Radom [31], was found to be very good. Based on the calculated $a b$ initio force field, a normal analysis was performed using local symmetry coordinates (available from the authors upon request). The potential energy distribution (Table 2) is rather localized, which supports the present choice of coordinates.

Usually, the spectral region below $600 \mathrm{~cm}^{-1}$ reflects any variation in the physical state of the sample, and is particularly useful when performing temperature-dependent conformational analysis [5-7]. In this study, however, no band intensity changes were detected when lowering the temperature from $25^{\circ} \mathrm{C}$ to $8^{\circ} \mathrm{C}$, in the liquid state, because of the rather high melting point of this compound $\left(8^{\circ} \mathrm{C}\right)$, that would ask for a broader temperature range to be investigated.

In the liquid phase, the Raman bands observed in the $250-600 \mathrm{~cm}^{-1}$ region - at 341,473 and $512 \mathrm{~cm}^{-1}$ - correspond to $\mathrm{CCN}$ deformation oscillators, in agreement with previous assignments reported for $n$-propylamine [5]. This is corroborated by the shift of those signals to lower frequencies upon N-deuteration. Based on the normal coordinate analysis now undertaken, it is possible to assign the band at $473 \mathrm{~cm}^{-1}$ to TTT conformer, and the ones at 341 and $512 \mathrm{~cm}^{-1}$ to the conformations displaying a skeletal gauche arrangement.

In the solid sample, the band at $430 \mathrm{~cm}^{-1}$ corresponds to the $\mathrm{NH}_{2}$ torsion, possibly overlapped in the liquid by the one at $340 \mathrm{~cm}^{-1}$, while the band at $470 \mathrm{~cm}^{-1}$ confirms the presence of only the TTT conformer in this phase. In aqueous solution this band is also clearly detected while the ones corresponding to gauche arrangements seem to disappear (Fig. 3).

From the normal coordinate results, the bands at 878,976 and $1086 \mathrm{~cm}^{-1}$ are ascribed to the conformers displaying a $\mathrm{G}$ orientation around the NCCN dihedral angle, namely to the most stable ones $\mathrm{TGG}^{\prime}$ and $\mathrm{GGG}^{\prime}$. These bands are not observed either in the solid sample or in the aqueous solution, which reflects the absence of those arrangements in the first case, or their very small population, in the second. Similarly, on N-deuterated system the bands at 880 and $932 \mathrm{~cm}^{-1}$ disappear in the solid state. Although the calculated wavenumbers agreeing better with the experimental ones are those assigned to conformer $\mathrm{TGG}^{\prime}$, the spectral evidence now obtained is not enough to exclude the presence of other conformational minima (e.g GGG'). All these bands are mainly ascribed to $\mathrm{CN}$ stretching modes, that were found to be rather sensitive to $\mathrm{NH}_{2}$ deuteration, as they were observed to shift ca. $40 \mathrm{~cm}^{-1}$ to lower frequencies in the liquid.

The $1099 \mathrm{~cm}^{-1}$ band, assigned to conformer TTT, was detected in the solid sample at $1109 \mathrm{~cm}^{-1}$, confirming the sole existence of this conformation in that phase (Fig. 3).

The bands due to the amine groups, in turn, are easily identified in the spectra, for they display clear frequency shifts upon deuteration. Thus, while the corresponding wagging, twisting and deformation modes occur at 841,1245 and $1600 \mathrm{~cm}^{-1}$, respectively, for 1,2-diaminoethane, the same oscillators are observed at 732,1001 and $1200 \mathrm{~cm}^{-1}$ for 1,2-diaminoethane- $\mathrm{N}-\mathrm{d}_{4}$. These bands were found to be slightly shifted to higher frequencies upon solidification of the sample (Fig. 3).

\section{Conclusions}

The ab initio conformational energies obtained for 1,2-diaminoethane suggest that the most stable conformers, both for the isolated molecule and the aqueous solution, are the ones where intramolecular (N)H $\cdots: \mathrm{N}$ hydrogen bonds can occur $\left(\mathrm{TGG}^{\prime}\right.$ and $\mathrm{GGG}^{\prime}$ ). The presence of such arrangements, displaying gauche skeletal orientations that favour 
the formation of those stabilizing interactions, was also detected in the Raman spectra of both the nondeuterated and $\mathrm{N}$-deuterated diamine, in the liquid phase, along with the all-trans conformer, In turn, its absence in the spectra of both the solid sample and the aqueous solution seems to indicate that the intermolecular interactions occurring in these systems are responsible for a marked change in the relative order of conformational stability predicted by ab initio methods. Indeed in aqueous solution the electrostatic effects that would favour the most polar conformations are overruled by the intermolecular hydrogen bonds formed with the solvent, that seem to prevail over the intramolecular interactions occurring in both the pure liquid and the gas.

Thus, although the ab initio calculations for the isolated molecule reproduce rather well the experimental data for the liquid phase, the results obtained with the SCRF are opposed to what is observed experimentally for the solution, as this method is based solely on dielectric characteristics of the solvent and does not consider the stabilising intermolecular $\mathrm{H}$ bonds.

The results now obtained clearly indicate the occurrence of distinct conformers in the liquid phase for this polyamine, varying in the central dihedral angle, as well as in the orientation of the nitrogen electron lone pairs. Thus, unlike in the solid phase, the conformational behaviour of this system is determined, in the liquid, by the possibility of formation of stabilising intramolecular hydrogen bonds, while in aqueous solution it seems to be less dependent on the dielectric characteristics of the solvent than on its capability to form specific intermolecular wateramine interactions.

\section{Acknowledgements}

The authors wish to acknowledge financial support from the Portuguese Foundation for Science and Technology - Project PBIC/C/QUI/2219/95.

\section{References}

[1] R.O. Duthaler, J.D. Roberts, J. Am. Chem. Soc. 100 (1978) 3889.
[2] J.J.C. Telxeira-Dias, L.A.E. Batista de Carvalho, A.M. Amorim da Costa, I.M.S. Lampreia, E.F.G. Barbosa, Spectrochim. Acta 42A (1986) 589.

[3] L.A.E. Batista de Carvalho, A.M. Amorim da Costa, J.J.C. Telxeira-Dias, E.F.G. Barbosa, I.M.S. Lampreia, J. Raman Spec. 18 (1987) 115.

[4] A.M. Amorim da Costa, L.A.E. Batista de Carvalho, J.J.C. Teixeira-Dias, E.F.G. Barbosa, I.M.S. Lampreia, Can. J. Chem. 65 (1987) 384.

[5] L.A.E. Batista de Carvalho, A.M. Amorim da Costa, M.L. Duarte, J.J.C. Teixeira-Dias, Spectrochim Acta 44A (1988) 723.

[6] L.A.E. Batista de Carvalho, A.M. Amorim da Costa, J.J.C. Teixeira-Dias, J. Molec. Struct. 218 (1990) 105.

[7] L.A.E. Batista de Carvalho, J.J.C. Telxeira-Dias, J. Raman Spec. 26 (1995) 653

[8] S. Jamet-Delcroix, Acta Cryst. B29 (1973) 977.

[9] R. Righini, S. Califano, Chem. Phys. 17 (1976) 45.

[10] A. Yokozeki, K. Kuchitsu, Bull. Chem. Soc. Jpn. 44 (1971) 2926.

[11] K.M. Marstokk, H. Mollendal, J. Molec. Struct. 49 (1978) 221.

[12] A. Sabatini, S. Califano, Spectrochim. Acta 16 (1960) 677.

[13] A. Diot, T. Theophanides, Can. J. Spec. 17 (1972) 67.

[14] Y. Omura, T. Shimanouchi, J. Mol. Spectrosc. 57 (1975) 480.

[15] M.G. Giorgini, M.R. Pelleti, G. Palliani, R.S. Cataliotti, J. Raman Spec. 14 (1983) 16.

[16] L. Radom, W.A. Lathan, W.J. Hehre, J.A. Pople, J. Am. Chem. Soc. 95 (1973) 693.

[17] K. Rasmussen, C. Tosi, Acta Chem. Scand. A37 (1983) 77.

[18] C. Van Alsenoy, K. Siam, J.D. Ewbank, L. Schater, J. Mol. Struct. (Theochem.) 136 (1986) 77.

[19] S.J. Lee, B.J. Mhin, S.J. Cho, J.J. Lee, K.S. Kim, J. Phys. Chem. 98 (1994) 1129.

[20] L.A.E. Batista de Carvalho, J.J.C. Teixeira-Dias, J. Mol. Struct. (Theochem) 282 (1993) 211.

[21] GAUSSIAN 94, Revision B 2, M.J. Frisch et al., Gaussian Inc., Pittsburgh PA, 1995.

[22] W.J. Hehre, R.F. Stewart, J.A. Pople, J. Am. Chem. Soc. 51 (1969) 2657.

[23] W.J. Hehre, R. Ditchfifeld, R.F. Stewart, J.A. Pople, J. Am. Chem. Soc. 52 (1970) 2769.

[24] J.S. Binkley, J.A. People, W.J. Hehre, J. Am. Chem. Soc. 102 (1980) 939.

[25] M.S. Gordon, J.S. Binkley, J.A. Pople, W.J. Pletro, W.J. Hehre, J. Am. Chem. Soc. 104 (1982) 2797.

[26] L.A.E. Batista de Carvalho, A.M. Amorim da Costa, J.J.C. Teixeira-Dias, J. Molec. Struct. (Theochem) 205 (1990) 327.

[27] P.C. Hariharan, J.A. Pople, Theor. Chim. Acta 28 (1973) 213.

[28] C. Moller, M.S. Plesset, Phys. Rev. 46 (1934) 618.

[29] M.W. Wong, K.B. Wiberg, M.J. Frisch, J. Am. Chem. Soc., 114 (1992) 1645 and references therein.

[30] W.J. Hehre, L. Radom, P.R. Schleyer, J.A. Pople, Ab Initio Molecular Orbital Theory, John Wiley and Sons, 1986.

[31] A.P. Scott, L. Radom, J. Phys. Chem. 100 (1996) 16502. 